\title{
ARTICLE
}

\section{Intramedullary spinal cord metastasis from colon cancer: analysis of 19 reported cases}

\author{
Tai-Hsin Tsai ${ }^{1,2,5}$, I-Cheng Lin ${ }^{1,5}$, Pei-Chen $\operatorname{Lin}^{3}$, Chieh-Hsin Wu ${ }^{1,2}$, Chih-Lung $\operatorname{Lin}^{1,2}$ and Yu-Feng Su ${ }^{1,4}$
}

We report and analyze a rare entity of intramedullary spinal cord tumor, which is metastatic from colon cancer with a very poor prognosis. The reported 19 cases including our case in the literature are analyzed. Comparison of outcomes between surgery, radiotherapy and non-treatment groups are evaluated. Life distribution is profiled. Median overall survival is 75 days. The 90 days and 150 days survival rate are $42.9 \%$ and $21.4 \%$, respectively. There were no differences between conservative treatment (non-treatment or radiotherapy) and aggressive intervention (surgery or surgery plus radiotherapy) in mortality and the trend of survival probability. The prognosis of metastatic intramedullary spinal cord tumor is poor. Surgery may only be considered in selected patients with good control of primary cancer and without evidence of lung metastases and leptomeningeal carcinomatosis.

Spinal Cord Series and Cases (2016) 2, 15026; doi:10.1038/scsandc.2015.26; published online 7 January 2016

\section{INTRODUCTION}

Intramedullary spinal cord metastasis (ISCM) is rare and found in $0.9-2.1 \%$ of all cancer patients. ${ }^{1}$ Lung is the major origin followed by breast cancer. Colorectal cancer accounts for about 3\% of ISCM cases $^{2}$ and only 18 cases have been reported. ${ }^{3}$ When diagnosed, the patients are usually in an advanced stage of diseases. ${ }^{2}$ Surgery and radiotherapy are usually the choices of treatment but there is no a consensus of management.

\section{CASE REPORT AND SERIES ANALYSIS}

A 66-year-old male patient has a history of ascending colon cancer (adenocarcinoma, pT3N2, grade II) diagnosed in 2012. He had neoadjuvant chemotherapy and received right hemicolectomy in October 2012. Adjuvant chemotherapy was applied but local recurrence was noted 8 months later. He had the second operation and kept adjuvant chemotherapy. Twenty-six months after the initial diagnosis, he was admitted to our hospital due to obstructive jaundice and progressive lower limbs weakness in December 2014. Abdominal computed tomography showed suspicious metastatic lymph nodes along with hepatoduodenal ligaments. Magnetic resonance imaging with enhancement identified an intramedullary spinal cord tumor at T9 level with perifocal edema (Figure 1). Obstructive jaundice was relieved with percutaneous transhepatic biliary drainage. Surgery of spinal cord tumor removal was performed then. During operation, midline myelotomy was performed after T9 and T10 laminectomy. A darkred and soft tumor was identified and removed. Metastatic adenocarcinoma was proved by pathology examination and immunohistochemistry study (Figures $1 \mathrm{~b}$ and c). The postoperative condition was uneventful initially but the muscle power of bilateral limbs did not improve. However, the patient had a biliary tract infection complicated with a rapid course of sepsis 2 weeks after the surgery. He refused aggressive treatment and died within days.

There have been only 19 cases of ISCM from colorectal cancer, including our case, reported in English literature (Table 1). ${ }^{4-7}$ Typical initial presentations are limbs weakness and numbness, which deteriorate rapidly. The time from initial neurological symptom to full deficit may be $<1$ month. ${ }^{8,9}$ Magnetic resonance imaging with enhancement is the modality of choice for diagnosis. ${ }^{4}$

Seven patients, including our case, underwent surgery; three patients received radiotherapy; two patients had surgery and then radiotherapy; two patients did not have any treatment and another four patients treatments were not available. Treatment with steroid was mentioned in three cases. The outcomes of 14 cases were described. Observed survival time is 2 weeks to 14 months. Survival analysis was calculated with Kaplan-Meier method (Figure 2a). Median overall survival is 75 days. The 90 days and 150 days survival rate are $42.9 \%$ and $21.4 \%$, respectively. There is no difference of survival rate between conservative treatment (non-treatment or radiotherapy) and aggressive intervention (surgery or surgery plus radiotherapy). Life distribution was profiled by groups. The trends of survival probability between groups (non-treatment, radiotherapy and surgery) do not exist difference significantly. The overall trend of life distribution is shown as Figure $2 b$.

\section{DISCUSSION}

ISCM is an uncommon manifestation of cancer, reported to affect $0.9-2.1 \%$ of all cancer patients. ${ }^{1}$ Metastasis from colorectal cancer is rare and reported to be $3 \%$ in all ISCMs. ${ }^{2}$ Only 19 cases including our case have been reported in English literature. ${ }^{4-7}$ In colorectal cancer patients, those who have lung metastases have higher risk of ISCM. ${ }^{10}$ Although ISCM has been reported

\footnotetext{
${ }^{1}$ Department of Neurosurgery, Kaohsiung Medical University Hospital, Kaohsiung, Taiwan; ${ }^{2}$ Graduate Institute of Medicine and Faculty of Medicine, College of Medicine, Kaohsiung Medical University, Kaohsiung, Taiwan; ${ }^{3}$ Research Center for Environmental Medicine, Kaohsiung Medical University, Kaohsiung, Taiwan and ${ }^{4}$ Graduate Institute of Clinical Medicine, College of Medicine, Kaohsiung Medical University, Kaohsiung, Taiwan.

Correspondence: Y-F Su (suyufeng2000@gmail.com)

${ }^{5}$ These two authors contributed equally to this work.

Received 28 May 2015; revised 1 September 2015; accepted 22 September 2015
} 

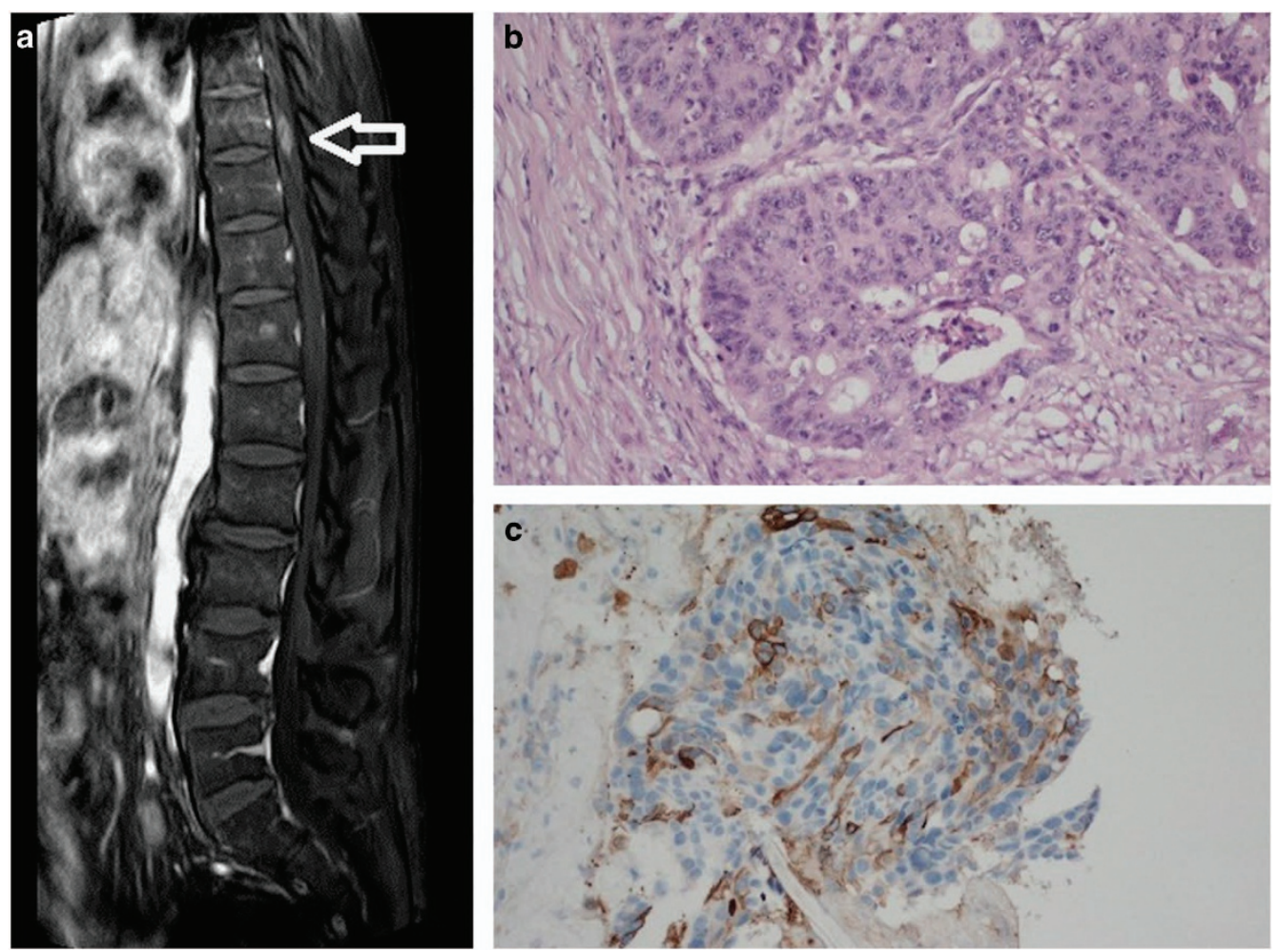

Figure 1. (a) Sagittal view of magnetic resonance imaging with enhancement showed an intramedullary spinal cord tumor at T9 level (arrow). (b) Section from the colon specimen showed adenocarcinoma composed of hyperchromatic and pleomorphic cancer cells arranged in glandular pattern with surrounding desmoplastic stroma. (c) Section from spinal cord lesion with immunohistochemistry stains showed neoplastic cells positive for cytokeratin 20 (CK20) but negative for cytokeratin 7 (CK7), caudal-related homeobox transcription factor 2 (CDX-2) and thyroid transcription factor-1 (TTF-1). The results were highly suggestive of metastatic adenocarcinoma.

\begin{tabular}{|c|c|c|c|c|c|c|c|c|c|}
\hline 2 & Silva \& McSwain ${ }^{18}$ & 1967 & C5-6 & $\mathrm{F}$ & 55 & 15 months & $-/+$ & Surgery & 15 days after operation \\
\hline 3 & Walker ${ }^{19}$ & 1967 & L1-2 & M & 56 & NA & $-/+$ & NA & NA \\
\hline 4 & Jellinger et al. ${ }^{20}$ & 1979 & T11-L2 & M & 77 & 5 years & $+/+$ & $\mathrm{Nil}$ & 3 weeks after admission \\
\hline $7 \& 8$ & Schiff \& O'Neill ${ }^{22}$ & 1996 & NA & NA & NA & NA & NA & NA & $\begin{array}{l}\text { NA (two cases in the series but no individual } \\
\text { details of treatment described) }\end{array}$ \\
\hline 9 & Ogino et al. ${ }^{10}$ & 2002 & C5-6 & M & 69 & 4 months & $-1-$ & Surgery & 3 months after operation due to dyspnea \\
\hline 10 & Yano et $a .^{23}$ & 2002 & $\mathrm{~T}$ & NA & & & & Surgery+RT & 5 months after surgery \\
\hline 11 & Kaya et al. ${ }^{24}$ & 2003 & T6 & $\mathrm{F}$ & 44 & 1 year & $+/ \mathrm{NA}$ & Surgery+ steroid & $\begin{array}{l}14 \text { months after operation, mediastinum } \\
\text { metastasis }\end{array}$ \\
\hline 12 & Grasso et al..$^{5}$ & 2007 & C3-4 & $\mathrm{F}$ & 61 & 0 & NA & Surgery & 2 months after operation \\
\hline 18 & Yang et al..$^{7}$ & 2014 & $\mathrm{~T} 12$ & M & 75 & 4 years & $\mathrm{NA} /+$ & $\mathrm{RT}+$ steroid & 4 months after ISDM diagnosed \\
\hline 19 & Su (our case) & 2014 & T9 & M & 66 & 26 months & $-/+$ & Surgery & 2 weeks after operation due to sepsis \\
\hline
\end{tabular}

Abbreviations: C, cervical; F, female; ISCM, intramedullary spinal cord metastasis; L, lumbar; M, male; NA, not available; RT, radiotherapy; T, thoracic.

to be the initial presentation of malignancy, ${ }^{5}$ most patients are diagnosed in an advanced stage of disease - One-third of patients had concomitant brain metastases and onequarter had leptomeningeal carcinomatosis when ISCM was diagnosed. ${ }^{2,11-13}$
As other metastatic lesions, ISCM is not curable. The goals of managements are usually achieving palliation, deferring neurological decline and sometimes for definite diagnosis. Treatment must be individualized and depends on condition of primary cancer, clinical performance and patient's expectance. 

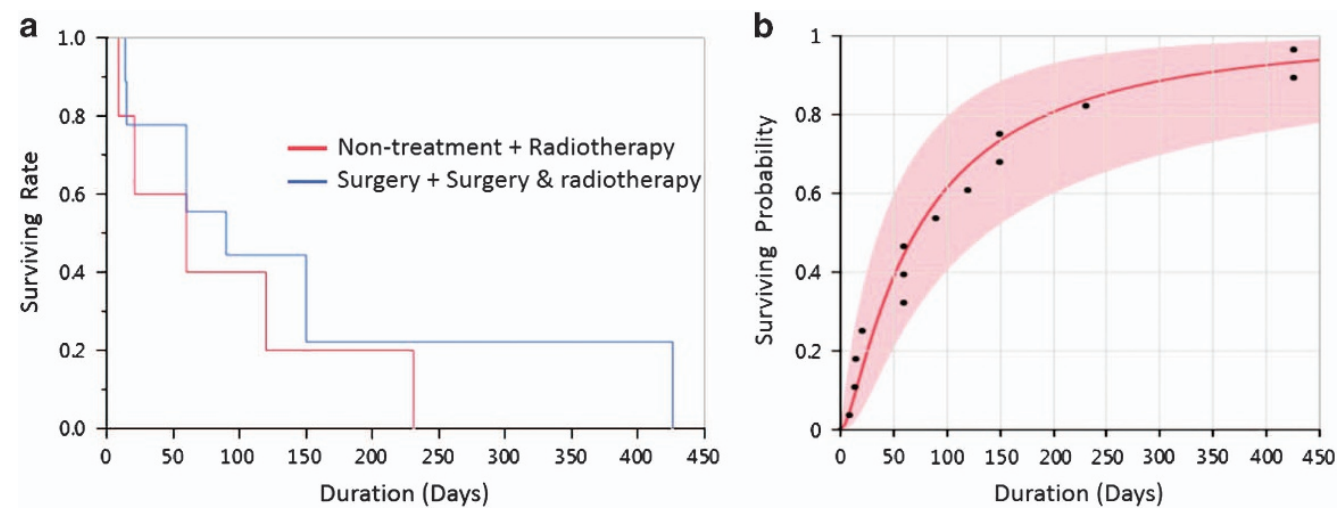

Figure 2. (a) There is no difference of survival rate between conservative treatment (non-treatment or radiotherapy) and aggressive intervention (surgery or surgery plus radiotherapy). (b) The overall trend of survival probability in 14 cases.

Our patient died of biliary tract infection 2 weeks after the surgery, a complication of lymph node metastases. Besides, disseminated metastasis of the primary cancer is usually the cause of death. Leptomeningeal carcinomatosis, multiple tumors and severe neurological impairment are relative contraindication for surgery. ${ }^{9}$

Recent studies have described longer survival in patients undergoing surgery. ${ }^{2,14,15}$ Dam-Hieu et al. retrospective reviewed 19 patients with ISCMs. The 13 patients who received operation have longer survival compared with those who did not (7.4 months vs 2.6 months). Moreover, 7 of the 13 operated patients had improvement of neurological status. ${ }^{9}$ Wilson et al. ${ }^{16}$ report 9 ISCM patients undergone operation and suggest operation may preserve neurological function if treated early.

Radiation is another option of treatment. It may suppress the tumor growth and expected to slow down neurological decline in radiosensitive tumors. Hashii et al. ${ }^{4}$ reported 18 ICSM patients receiving radiotherapy, the 3-month and 6-month survival rate were $54 \%$ and $36 \%$, respectively. Median overall survival was 4 months. In the review of ISCM from colon cancer, four patients had radiotherapy and three of them died within 5 months after diagnosed of ISCM. The effect of radiotherapy varies between different pathologies and colon adenocarcinoma unfortunately is not a radiosensitive one.

There is still no guideline for management of ISCM. The treatment usually depends on physician's experience. Conservative treatment is often the first choice due to the dismal prognosis of ISCM and the poor clinical condition of the patients. Surgery has its role in ISCMs originated from colorectal cancer in selected patients. The candidates for operation may be with well-controlled of the primary cancers, no lung metastases and no leptomeningeal carcinomatosis. The functional outcome and quality of life after surgery may be improved if the intervention can be provided early.

\section{CONCLUSION}

Patients with ISCM usually have concomitant disseminated systemic metastases and have poor prognosis even under aggressive treatment. Surgical treatment may prolong survival in selected patients. More study is needed to compare the effects of radiotherapy and surgery and to figure out which groups of patients might benefit from surgery.

\section{AUTHOR CONTRIBUTIONS}

$\mathrm{T}-\mathrm{HT}, \mathrm{I}-\mathrm{CL}$ and $\mathrm{Y}-\mathrm{FS}$ conceived and designed the work that led to the submission. I-CL and Y-FS acquired data and references. P-CL had an important role in interpreting the results. T-HT, I-CL and Y-FS drafted and revised the manuscript. T-HT and I-CL contributed equally to the working as a first author. Y-FS and C-LL approved the final version.

\section{COMPETING INTERESTS}

The authors declare no conflict of interest.

\section{REFERENCES}

1 Costigan DA, Winkelman MD. Intramedullary spinal cord metastasis. A clinicopathological study of 13 cases. J Neurosurg 1985; 62: 227-233.

2 Kalayci M, Cagavi F, Gul S, Yenidunya S, Acikgoz B. Intramedullary spinal cord metastases: diagnosis and treatment-an illustrated review. Acta Neurochir (Wien) 2004; 146: 1347-1354. Discussion 1354.

3 Lunardi P, Corinaldesi R, Lunardi T, Floris R. Solitary intramedullary spinal cord metastasis from colon carcinoma: a case report and literature review. Open J Mod Neurosurg 2014; 04: 47-51.

4 Hashii $\mathrm{H}$, Mizumoto $\mathrm{M}$, Kanemoto A, Harada $\mathrm{H}$, Asakura $\mathrm{H}$, Hashimoto $\mathrm{T}$ et al. Radiotherapy for patients with symptomatic intramedullary spinal cord metastasis. J Radiat Res 2011; 52: 641-645.

5 Grasso G, Meli F, Patti R, Giambartino F, Florena AM, lacopino DG. Intramedullary spinal cord tumor presenting as the initial manifestation of metastatic colon cancer: case report and review of the literature. Spinal Cord 2007; 45: 793-796.

6 Vassiliou V, Papamichael D, Polyviou P, Koukouma A, Andreopoulos D. Intramedullary spinal cord metastasis in a patient with colon cancer: a case report. J Gastrointest Cancer 2012; 43: 370-372.

7 Yang $\mathrm{KH}$, Lee HR, Yi SY, Jung JH, Kang SH, Choi PH. Intramedullary spinal cord metastasis from rectal cancer. Ann Coloproctol 2014; 30: 237-240.

8 Watanabe M, Nomura T, Toh E, Sato M, Mochida J. Intramedullary spinal cord metastasis: a clinical and imaging study of seven patients. J Spinal Disord Tech 2006; 19: 43-47.

9 Dam-Hieu P, Seizeur R, Mineo JF, Metges JP, Meriot P, Simon H. Retrospective study of 19 patients with intramedullary spinal cord metastasis. Clin Neurol Neurosurg 2009; 111: 10-17.

10 Ogino M, Ueda R, Nakatsukasa M, Murase I. Successful removal of solitary intramedullary spinal cord metastasis from colon cancer. Clin Neurol Neurosurg 2002; 104: 152-156.

11 Lee SS, Kim MK, Sym SJ, Kim SW, Kim WK, Kim SB et al. Intramedullary spinal cord metastases: a single-institution experience. J Neurooncol 2007; 84: 85-89.

12 Sung WS, Sung MJ, Chan JH, Manion B, Song J, Dubey et al. Intramedullary spinal cord metastases: a 20-year institutional experience with a comprehensive literature review. World Neurosurg 2013; 79: 576-584.

13 Connolly ES Jr, Winfree CJ, McCormick PC, Cruz M, Stein BM. Intramedullary spinal cord metastasis: report of three cases and review of the literature. Surg Neurol 1996; 46: 329-337. Discussion 337-8.

14 Gasser T, Sandalcioglu IE, El Hamalawi B, van de Nes JA, Stolke D, Wiedemayer H. Surgical treatment of intramedullary spinal cord metastases of systemic cancer: functional outcome and prognosis. I Neurooncol 2005; 73: $163-168$.

15 Hrabalek L. Intramedullary spinal cord metastases: review of the literature. Biomed Pap 2010; 154: 117-122.

16 Wilson DA, Fusco DJ, Uschold TD, Spetzler RF, Chang SW. Survival and functional outcome after surgical resection of intramedullary spinal cord metastases. World Neurosurg 2012; 77: 370-374. 
17 Sansoy OM. Intramedullary spinal cord metastasis from carcinoma of the colon simulating acute ascending myelitis. Mo Med 1955; 52: 864-866.

18 Silva YJ, McSwain B. Intramedullary spinal cord metastasis: the sole clinical manifestation of an adenocarcinoma of the colon. Can J Surg 1967; 10: 341-344.

19 Walker LG Jr. Intramedullary spinal cord metastasis from carcinoma of the colon. Am Surg 1967; 33: 422-424.

20 Foster OJ, Crockard HA. Cervical syrinx associated with an intramedullary metastasis: case report. J Neurol Neurosurg Psychiatry 1987; 50: 637-639.

21 Jellinger K, Kothbauer $\mathrm{P}$, Sunder-Plassmann E, Weiss R. Intramedullary spinal cord metastases. J Neurol 1979; 220: 31-41.

22 Schiff D, O'Neill BP. Intramedullary spinal cord metastases: clinical features and treatment outcome. Neurology 1996; 47: 906-912.
23 Yano S, Hida K, Seki T, Iwasaki Y, Chouno Y, Sugimoto S et al. [Intramedullary spinal cord metastasis: two case reports and literature review]. No Shinkei Geka 2002; 30: 189-196.

24 Kaya RA, Dalkilic T, Ozer F, Aydin Y. Intramedullary spinal cord metastasis: a rare and devastating complication of cancer--two case reports. Neurol Med Chir (Tokoyo) 2003; 43: 612-615

25 Kaballo MA, Brennan DD, El Bassiouni M, Skehan SJ, Gupta RK. Intramedullary spinal cord metastasis from colonic carcinoma presenting as Brown-Sequard syndrome: a case report. J Med Case Reports 2011; 5: 342.

26 Vassiliou V, Papamichael D, Polyviou P, Koukouma A, Andreopoulos D. Intramedullary spinal cord metastasis in a patient with colon cancer: a case report. J Gastrointest Cancer 2012; 43: 370-372. 